mel grains. Since the size of particles produced by grinding will not always be the same, this method of preparing the electrode should be abandoned and the method of shaking should always be employed. Sauer's further conclusion that the potential is different when mercury is present in small drops in the electrode paste we have not been able to corroborate. Electrodes made in the usual way with finely divided mercury in the "paste" gave the same result as those in which this paste was replaced by pure calomel. It is however advisable to use the paste, since the large surface of mercury which it offers enables the electrode to come to equilibrium more quickly when subjected to temperature changes or other disturbances.

[CONTRtButions From the Research Laboratory of Physical Chemistri of the Massachusetts Institute of Technology, No. 34.]

\title{
POTENTIALS BETWEEN LIQUIDS.
}

By Gilbert N. LeWIS aNd Ledyard W. SARgent.

Received January 25, 1909

In conducting a series of investigations upon electrode potentials we have found it necessary to study also the potentials which exist at the boundary between two contiguous solutions, for these potentials almost invariably enter when another electrode is compared with the normal electrode. These liquid potentials have been the subject of extensive theoretical treatment and the formulae which have been obtained by Nernst, Planck, and others have been frequently tested experimentally. The values found have usually agreed with those calculated from theory within a few millivolts, ${ }^{1}$ that is, within the custom.ry limits of experimental error. It seems desirable, however, to subject the formulae to a severer test.

This paper will deal with a single type of potentials between liquids, namely, with the potential between equally concentrated solutions of two binary salts having one ion in common. To such a case we may apply the familiar equation of Planck,

$$
\mathrm{E}=\mathrm{RT} / \mathrm{F} \ln \left(u_{1}+v_{1}\right) /\left(u_{2}+v_{2}\right),
$$

where $R, T$, and $F$ have their customary significance, $\ln$ stands for natural logarithm, $\mathrm{E}$ is the potential at the boundary between the two solutions, $n$ the valence of all the ions, $u_{1}$ and $u_{2}$ the so-called mobilities (or equivalent conductivities at infinite dilution) of the cations; $v_{1}$ and $v_{2}$, of the anions. If the ions are univalent and one ion is common to both solutions we have either,

${ }^{1}$ Negbaur (Ann.d. Phys., 44, 73I) found in several cases a more exact agreement between his observed potentials and those calculated from Planck's equation. But his experiments have not been corroborated by the later experiments of Jahn, Sauer, and others. 


$$
\text { or, } \quad \begin{aligned}
\mathrm{E} & =\mathrm{RT} / \mathrm{F} \ln \left(u_{1}+v_{1}\right)\left(u_{2}+v_{2}\right), \\
\mathrm{I} i & =\mathrm{R} T / \mathrm{F} \ln \left(u+v_{1}\right) /\left(u+i_{2}\right) .
\end{aligned}
$$

If the equivalent conductivity at infinite dilution of the first solution is represented by $\lambda_{01}$ and of the second solution by $\lambda_{02}$ then obviously by c. inition we may write $\lambda_{01}$ equal to $u_{1}+v$ (or $u+v_{1}$ ), and $\lambda_{02}$ equal tc $u_{2}+v$ (or $\left.u+v_{2}\right)$. Both equations then become,

$$
\mathrm{I}=\mathrm{RT} / \mathrm{F} \ln \lambda_{01} / \lambda_{02} \text {. }
$$

When both solutions are at the same concentration, and equally dissociated, the ratio of the equivalent conductivities at the given concentration, $\lambda_{1} / \lambda_{2}$, is equal to $\lambda_{0} / \lambda_{02}$ and we may therefore write in place of (2)

$$
\mathrm{E}=\mathrm{RT} / \mathrm{F} \ln \lambda_{1} / \lambda_{2}
$$

In making this substitution we have assumed that the ionic mobilities are independent of the concentration, which is the assumption upon which Planck bases his equations. If it is correct, equations (2) and (3) are identical, but if it is incorrect, and the mobility of the ions change with the concentration, as it does in the case of a number of important ions, notably hydrogen ion, ${ }^{1}$ we may expect equation (3) to be true rather than equation (2), for $\lambda_{1}$ and $\lambda_{2}$ depend upon the actual mobilities of the ions at the given concentration. We shall see in fact that equation (3) agrees better with the results of experiment than equation (2) and, moreover, appears to be applicable even when the two solutions are dissociated to a somewhat different extent.

The experiments of Sauer ${ }^{2}$ on the calomel electrode furnish one very exact determination from which an important liquid potential may be obtained. He measured at $18^{\circ}$ the difference in potential between two calomel electrodes, one in tenth-normal potassium chloride, the other in tenth-normal hydrochloric acid, and found as a mean of 6 careful measurements 0.0286 volt. This is the sum of the two electrode potentials and the potential between the solutions. The former depend solely upon the concentration of chloride ion on the two sides. There was formerly supposed to be a considerable difference between these two concentrations owing to the apparently greater dissociation of the acid, as determined from conductivities. Noyes and Sammet have shown, however, that this is due to a gradual increase in the mobility of hydrogen ion with the concentration. If a correction is made for this, the hydrochloric acid and potassium chloride prove to be equally dissociated. The two electrode potentials are therefore equal, and the whole measured potential difference of 0.0286 volt is simply the potential between the

${ }^{1}$ Noyes and Sammet: This JourNal, 24, 758: 25, I67 (Igo2-3).

2Z. physik, Chem., 47, I46 (1904). 
liquids. Calculating this potential from equation (3), using the conductivities of Kohlrausch, ${ }^{1}$ we find the identical value, 0.0286 volt, a very striking agreement. Planck's equation (2) gives 0.027 I volt.

The method which we have used for the determination of potentials between liquids is similar to the one just employed. We have shown in the previous paper that a gold electrode in a solution of a potassium salt containing small quantities of potassium ferro- and ferricyanides gives a well defined potential which depends only upon the concentration of potassium ion and the ratio of ferro- to ferricyanide. If then two such electrodes in solutions of two different potassium salts of the same potassium ion concentration, and containing the same quantities of ferro- and ferricyanide, are joined together, the two electrode potentials will balance, and the whole potential will be the potential between the liquids. Even if the two potassium ion concentrations are not equal it is an easy matter to calculate the small correction from the results of our preceding paper and thus determine that part of the observed potential which is due to the liquid junction.

The substances used in these experiments were of a high grade of purity and the concentrations were carefully determined. Potassium acetate was determined by evaporating to dryness, treating with hydrochloric acid, and weighing as chloride. Potassium hydroxide was made by mixing solutions of potassium sulphate and of barium hydroxide (twice recrystallized in porcelain) until the solution gave no precipitate in five minutes with either a sulphate or a barium salt. Sodium hydroxide was prepared in the same way.

The potentials between the following pairs of liquids at $25^{\circ}$ were determined. Each value given is the mean of at least six and usually of a much larger number of measurements. A positive sign indicates that the positive current tends to pass from the first solution to the second.

$0.2 \mathrm{~N} \mathrm{KCl}-0.2 \mathrm{~N} \mathrm{KC}_{2} \mathrm{H}_{3} \mathrm{O}_{2}$. - The measured potential was - 0.0069 volt. According to the conductivity measurements the chloride is 5 per cent. more dissociated than the acetate. ${ }^{2}$ The correction for the difference in electrode potentials is thus $-0.00 \mathrm{I}$ and $\mathrm{E}$, the potential between the liquids is -0.0080 .

o. I $\mathrm{N} \mathrm{KCl}$ - O. I $\mathrm{N} \mathrm{KC}_{2} \mathrm{H}_{3} \mathrm{O}_{2}$. -The measured potential was - 0.0069 .

' o.I $n \mathrm{KCl}, \lambda=112.0 ; 0.1 n \mathrm{HCl}, \lambda=351.0 ; \mathrm{KCl}, \lambda_{0}=130.1 ; \mathrm{HCl}, \lambda_{0}=383.0$ (Landolt and Bornstein).

2 The ratio of the degrees of dissociation is assumed to be the same at $25^{\circ}$ as at $18^{\circ}$, which is unquestionably the case within the limits of error. The calculations are based on the observation of the previous paper that the potential of the ferro-ferticyanide electrode changes $0.0002 \mathrm{I}$ volt in the neighborhood of $0.2 n$ and 0.00019 volt in the neighborhood of $0 . I n$, when the potassium ion concentration changes I per cent. 
The chloride is 2.5 per cent. more dissociated. The correction is, therefore, -0.0005 and $E=-0.0074$.

$0.2 \mathrm{~N} \mathrm{KCl}-0.2 \mathrm{~N} \mathrm{KOH}$. . The potential in potassium hydroxide solutions proved to be inconstant, owing apparently to local decomposition, but when the electrode was vigorously tapped, so as to keep the neighboring electrolyte in circulation, constant and reproducible values were obtained. When both solutions were $0.004 N$ with respect to both ferro- and ferricyanide the potential observed was 0.0161 , when $0.008 \mathrm{~N}$ the potential was also $0.016 \mathrm{I}$. (Preliminary measurements with platinum and iridium electrodes gave 0.0159 .) The hydroxide is 4.5 per cent. more dissociated ${ }^{1}$ than the chloride. The correction is therefore 0.0009 and $\mathrm{E}=0.0170$.

o. I N KCl-o.I N KOH. -The electrodes were tapped. With both solutions $0.004 N$ with respect to ferro- and ferricyanide the potential was found to be $0.0156+$; with $0.008 \mathrm{~N}, 0.0157$. The hydroxide is 4 per cent. more dissociated and the correction is $0.0008 . \mathrm{E}=0.0165$.

$0.2 \mathrm{~N} \mathrm{KCl}-0.2 \mathrm{~N} \mathrm{KBr}$. The potential measured was 0.0004 . The two salts are equally dissociated. Hence $\mathrm{E}=0.0004$.

$0.2 \mathrm{~N} \mathrm{NaCl}-0.2 \mathrm{~N} \mathrm{NaOH}$.--The potential between these two liquids was measured in the same way as the others by adding equal amounts of potassium ferro- and ferricyanide to the two sides. Strictly speaking, the corresponding sodium salts should have been used, but because of the small amount of ferro-ferricyanide added the results would doubtless have been the same. In this case for some reason which we were unable to determine, the potentials were somewhat inconstant in spite of continued tapping. The most probable result is $0.0181 \pm 0.0003$. The hydroxide is 6.5 per cent. more dissociated. The resulting correction is $0.001 \mathrm{I}$ and $\mathrm{E}=0.0192 \pm 0.0003$.

In order to compare these experimental values with those calculated from equation (3) the molecular conductivity at $25^{\circ}$ was carefully measured for each solution. The results are given in the following table:

$\begin{array}{lccccc} & \mathrm{KCl} & \mathrm{NaCl} & \mathrm{KOH} . & \mathrm{NaOH} . & \mathrm{KC}_{2} \mathrm{H}_{3} \mathrm{O}_{2} . \\ \text { O. I N } & 128.8 & \text { IO6.9 } & 245.3 & 2 \mathrm{I} 9 . \mathrm{I} & 95.3 \\ 0.2 \mathrm{~N} & 123.9 & \mathrm{IOI} .9 & 238.4 & 2 \mathrm{II} . \mathrm{O} & 90 . \mathrm{I}\end{array}$

The next table gives the observed values of $\mathrm{E}$ and those calculated from equation (3). The average difference between the calculated and the observed values is hardly more than a tenth of a millivolt.

1 The high degree of dissociation calculated for the hydroxides may possibly, as in the case of acids, be only apparent and due to a change of mobility of the hydroxide ion with the concentration. At present, however, we have no experimental evidence on this point. 


\begin{tabular}{|c|c|c|c|c|}
\hline $0.2 n \mathrm{KCl}$ & $-0.2 n \mathrm{KC}_{2} \mathrm{H}_{3} \mathrm{O}_{2}$ & $\begin{array}{r}\text { E (obs.). } \\
-0.0080\end{array}$ & $\begin{array}{c}E(c a l c .) \text {. } \\
-0.0082\end{array}$ & $\begin{array}{c}\mathrm{E} \text { (obs.) }-\mathrm{E} \text { cal. } \\
0.0002\end{array}$ \\
\hline $0.1 n \mathrm{KCl}$ & $\longrightarrow . I n \mathrm{KC}_{2} \mathrm{H}_{3} \mathrm{O}_{2}$ & -0.0074 & -0.0077 & 0.0003 \\
\hline $0.2 n \mathrm{KCl}$ & $\multimap .2 n \mathrm{KOH}$ & 0.0170 & 0.0168 & 0.0002 \\
\hline o. $1 n \mathrm{KCl}$ & $-0.1 n \mathrm{KOH}$ & 0.0165 & 0.0165 & 0.0000 \\
\hline $0.2 n \mathrm{KCl}$ & $-0.2 n \mathrm{KBr}$ & 0.0004 & $0.0004^{1}$ & 0.0000 \\
\hline $0.2 n \mathrm{NaCl}$ & $-0.2 n \mathrm{NaOH}$ & $0.0192 \pm 0.0003$ & 0.0187 & $\ldots \ldots$ \\
\hline o. I $n \mathrm{KCl}$ & 一. I $n \mathrm{HCl}$ & -0.0286 & -0.0286 & 0.0000 \\
\hline
\end{tabular}

\section{Summary.}

The potentials between six pairs of liquids were determined by a new method. The results agree remarkably well with a modified form of the Planck equation. The conductivities at $25^{\circ}$ were accurately determined for all the liquids used.

[CONTRIBUtion FROM THE KENT Chemical Laboratory OF THE UNIVERSTTY OF Chicago.]

\section{THE SPEED OF OXIDATION, BY AIR, OF URANOUS SOLUTIONS, WITH A NOTE ON THE VOLUMETRIC DETERMINATION OF URANIUM.}

BY HERBERT N. MCCOY AND HERBERT H. BUNZEL.

Received December 18, 1908.

The simplest volumetric method for the determination of uranium is that in which the element is converted into uranyl sulphate, $\mathrm{UO}_{2} \mathrm{SO}_{4}$, reduced with zinc and sulphuric acid to uranous sulphate, $\mathrm{U}\left(\mathrm{SO}_{4}\right)_{2}$, and titrated with standard permanganate. ${ }^{2}$ The procedure is analogous to the reduction of ferric salts to ferrous and titration of the latter. There is, however, an important difference: uranous solutions oxidize in ais far more rapidly than ferrous solutions. In order to learn, quite definitely, what influence atmospheric oxidation might have upon the accuracy of the volumetric determination of uranium, we have made some experiments on the speed of oxidation of uranous sulphate by air.

The uranous solution was prepared just as in the process of analysis: $25 \mathrm{cc}$. of $\mathrm{N} /$ ro uranyl sulphate solution (I I.925 grams of uranium per liter) were mixed with IOO cc. of $6 \mathrm{~N}$ sulphuric acid (294 grams $\mathrm{H}_{2} \mathrm{SO}_{4}$ per liter) and reduced with 100 grams of pure stick zinc at $100^{\circ}$, for I 5 minutes. The reduced solution was separated from the zinc, diluted to $250 \mathrm{cc}$. and divided into two portions, each of which was placed in a Drechsel wash bottle and kept at $25^{\circ} \pm 0.01$. Air at atmospheric pressure, and satu-

1 Through an oversight the conductivity of $\mathrm{KBr}$ was not measured. However, equation (2) will probably in this case give the same result as equation (3). The above calculated value of $\mathrm{E}$ was obtained from equation (2), Kohlrausch's values for the ionic mobilities and their temperature coefficients being used.

2 Kern, This Journal, 23, 685 (I901); Pulman, Amer. J. Sci., 16, 229 (1903); Goettsch, This Journai, 28, 154 I (1906). 